\title{
Pulmonary atresia-intact ventricular septum syndrome
}

INSERM

\section{Source}

INSERM. (1999). Orphanet: an online rare disease and orphan drug data base. Pulmonary atresia-intact ventricular septum syndrome. ORPHA:1208

Pulmonary atresia with intact ventricular septum (PA-IVS) is a rare form of cyanotic congenital heart malformation characterized by severe cyanosis and tachypnea. PA-IVS presents significant morphologic diversity: at the end of the spectrum are patients with a mildly hypoplastic and tripartite right ventricle (RV) and mild tricuspid valve (TV) hypoplasia, and at the other end are patients with severe RV and TV hypoplasia, often with RV-dependent coronary circulation. 